\title{
POLA KEPENULISAN DAN KOLABORASI PENELITIAN PADA JURNAL TREUBIA
}

\author{
Sri Wulan* \\ Pusat Penelitian Biologi - LIPI \\ *Korespondensi: sriwulanhar@yahoo.com
}

Diajukan: 24 Agustus 2017; Direview: 11 September 2017; Diterima: 25 September 2017; Direvisi: 31 Oktober 2017

\begin{abstract}
Studies on the pattern of authorship and the level of research collaboration have been done by many scientific journals, but the study on the journal Treubia has never been done.The Journal Treubia is an english language journal of the Indo-Australian animal taxonomy. Established in 1919 by the director of Plantetuin Lands (now botanical garden) named Dr. M. Treub, for the first time this journal discussed only on plant pests. Now, Treubia is an English-language scietific journal focus on biosystematic, ecological, and conservation aspects of terrestrial and aquatic fauna in the Indo-Australian region. This aim of this study is to determine the pattern of the authorship and the level of collaborative research in the journal Treubia during period 2006-2016. The method used in this study is descriptive by using the data from journal article of Treubia, Research Center for Biology-Indonesian Institute of Sciences. Collection and processing data were conducted in March 2017. The results show that during the period 2006-2016, journal Treubia produced 50 articles. The most authors are male with $91(71.1 \%)$ of the 128 authors. Furthermore, by country, Indonesia is the biggest contributor with 86 authors $(67.19 \%)$ and the lowest is Australia, Singapore, and Vietnam each of them with 1 author (0.78\%). The document type most highly cited is the journals which has been cited in 1,307 papers, and then newsletter and map which have been cited in 1 paper. The author's collaboration rate is 0.7 with the author's index per article is 2.56 . Both of numeral rate and index are the positive criterion for assessing the higher quality of published papers.
\end{abstract}

\begin{abstract}
ABSTRAK
Kajian mengenai pola kepeulisan dan tingkat kolaborasi sudah banyak dilakukan oleh jurnal-jurnal ilmiah lainnya, namun kajian terhadap jurnal Treubia belum pernah dilakukan. Jurnal Treubia adalah jurnal berbahasa Inggris mengenai taksonomi hewan Indo-Australian. Awal didirikan tahun 1919 oleh direktur 's Lands Plantetuin (sekarang kebun raya) bernama Dr. M. Treub. Jurnal ini membahas mengenai hama tanaman. Kajian ini bertujuan untuk mengetahui pola kepenulisan dan tingkat kolaborasi penelitian pada jurnal Treubia 2006-2016. Metode penelitian yang digunakan adalah metode deskriptif dengan menggunakan data artikel jurnal Treubia Puslit Biologi LIPI selama periode 2006-2016. Pengambilan dan pengolahan data dilakukan pada bulan Maret 2017. Hasil kajian menunjukkan jurnal Treubia selama periode 2006-2016 menghasilkan artikel sebanyak 50 artikel. Penulis pria menduduki posisi terbanyak 91 $(71,1 \%)$ dari 128 penulis. Kontribusi penulis berdasarkan negara yaitu dari Indonesia 86 (67,19\%) dan terendah dari Australia, Singapura dan Vietnam sebesar $1(0,78 \%)$. Jenis dokumen yang disitir yaitu jurnal menduduki posisi teratas 1.307 artikel, newsletter dan peta sebesar 1 artikel. Tingkat kolaborasi penulis sebesar 0,7 dengan indeks penulis per artikel 2,56. Angka ini merupakan kriteria positif untuk menilai semakin tingginya kualitas penelitian yang dihasilkan.
\end{abstract}

Keywords: Authorship patterns; Research Collaboration; Bibliometrics; Content Analysis

\section{PENDAHULUAN}

Suatu penelitian tidak akan bermanfaat apabila tidak diketahui masyarakat. Oleh karena itu, hasil penelitian perlu dipublikasikan dalam bentuk terbitan berkala yang berkualitas, seperti jurnal, prosiding, buku, makalah, atau bentuk format lainnya. Hasil-hasil penelitian perlu adanya upaya penyebarluasan kepada masyarakat ilmiah baik dalam negeri maupun luar negeri. 
Terbitan berkala merupakan salah satu sarana komunikasi yang sangat penting dalam menunjang perkembangan ilmu pengetahuan.

Treubia merupakan jurnal taksonomi hewan berbahasa Inggris yang telah mencapai tahun terbitan ke-97. Didirikan awal tahun 1919 oleh direktur 's Lands Plantetuin (sekarang kebun raya) bernama Dr. M. Treub. Jurnal ini membahas mengenai hama tanaman (Kadarsan, 1994). Pengabdian yang sekian lama tentunya sangat memberikan kontribusi dalam perkembangan ilmu pengetahuan khususnya dalam bidang ilmu taksonomi hewan IndoAustralian.

Meskipun kajian mengenai pola kepenulisan dan tingkat kolaborasi sudah banyak dilakukan oleh peneliti sebelumnya (Aliyu, 2011; Arya \& Sharma, 2012; Cunningham \& Dillon, 1997; Raptis,, 1992; Vimala \& Reddy, 1996; Subramanyam, 1983) namun kajian terhadap jurnal Treubia belum ada penelitian sebelumnya. Sehingga kajian ini penting dilakukan untuk mengetahui sebaran dan tingkat kolaborasi penelitian pada jurnal Treubia selama 20062016.

\section{TINJAUAN PUSTAKA}

Bibliometrika adalah salah satu cabang paling tua dari Ilmu Perpustakaan (Pendit, 2008). Bibliometrika merupakan komponen dari matematika, ilmu sosial, ilmu alam, teknik dan bahkan ilmu hayati (Glanzel, 2008). Prithchard (1969) adalah orang yang pertama kali memperkenalkan analisis bibliometrika yang telah banyak digunakan untuk mengkaji pemanfaatan literatur dan dokumen dari berbagai disiplin ilmu. Analisa bibliometrika bertujuan untuk menjelaskan proses komunikasi tertulis, sifat, dan arah pengembangan sarana deskriptif penghitungan dan analisis berbagai faset komunikasi (Sulistyo, 2002).

Kepenulisan merupakan salah satu aspek yang berperan penting dalam penyebaran informasi dan kegiatan komunikasi. Kontribusi penulis dapat dilihat dari pola yang berbeda, seperti penulis tunggal, penulis bersama, dan beberapa penulis (Aliyu, 2011).

Kolaborasi merupakan terjemahan dari kata "collaboration" yang artinya kerjasama. Kolaborasi mencakup semua kegiatan yang ingin dicapai dan mempunyai tujuan serta manfaat bersama. Katz and Martin (1997) memberikan batasan bahwa seorang peneliti dikatakan berkolaborasi apabila mereka bekerjasama dalam proyek penelitan, namanya muncul dalam proposal penelitian, bertanggung jawab dalam satu atau lebih elemen penelitian, pelaksanaan eksperimen, analisa dan interpretasi data, serta penulisan laporan. Das (2013) menyebutkan bahwa kolaborasi adalah bentuk interaksi dalam membina komunikasi yang efektif serta berbagi kompetensi dan sumber daya lainnya dalam mencari ilmu pengetahuan baru.

Kajian ini bertujuan untuk mengetahui sebaran artikel setiap tahun, pola kepenulisan setiap tahun, kepenulisan perorangan dan gabungan, rata-rata penulis per artikel, sebaran artikel berdasarkan jenis kelamin, kontribusi penulis berdasarkan negara, serta jenis dokumen yang disitasi pada artikel Jurnal Treubia. Dari tujuan kajian yang hendak dicapai paling tidak akan memberikan gambaran upaya kongkrit peneliti dalam peningkatan kepenulisan dalam jurnal Treubia tercermin dari ciri-ciri artikel jurnal tersebut.

Kajian ini diharapkan bermanfaat untuk mengetahui kualitas artikel dan tingkat kolaborasi penelitian pada jurnal Treubia 2006-2016 dan memberi manfaat bagi pemangku kepentingan khususnya di Puslit Biologi-LIPI dalam merencanakan kegiatan kerjasama riset dengan peneliti asing, sehingga hasil kerjasama dapat dituangkan dalam jurnal Treubia untuk meningkatkan aksesibilitas secara global. 


\section{METODE}

\subsection{Pengumpulan Data}

Kajian dilakukan terhadap jurnal Treubia selama 10 volume terakhir tahun 2006 sampai 2016, kecuali tahun 2009 karena tahun tersebut tidak menerbitkan namun untuk nomor volume tetap berlanjut. Pola kepenulisan yang diteliti diantaranya: sebaran artikel per tahun, jenis kelamin penulis, asal negara penulis, profil kontribusi penulis, tingkat kolaborasi penulis. Pola sitiran yang diteliti mencakup jumlah sitiran dan jenis dokumen yang disitir.

Pengkajian dilakukan pada Bulan Maret 2017. Kajian ini merupakan kajian analisis deskriptif kuantitatif. Metode yang digunakan adalah analisis bibliometrik untuk mempelajari secara detail tampilan bibliometrik dari suatu artikel dan analisis jenis referensi yang ditambahkan pada setiap akhir artikel. Data yang diambil sebanyak 50 artikel dari vol 34 (2006) sampai vol 43 (2016).

\subsection{Pengolahan Data}

Data yang diperoleh kemudian diolah dengan bantuan Microsoft Excel 2010. Tujuannya untuk memperoleh data awal dan memudahkan dalam pendistribusian data dan tampilan dalam format grafik. Pengolahan data digunakan untuk menentukan:

- penyebaran artikel Jurnal Treubia 2006-2016;

- pola kepenulisan setiap tahun;

- kepenulisan perorangan dan gabungan;

- rata-rata penulis per artikel;

- sebaran artikel berdasarkan jenis kelamin;

- kontribusi penulis berdasarkan negara;

- jenis dokumen yang disitasi oleh penulis pada artikel jurnal treubia.

\subsection{Analisis Data}

Formula yang digunakan untuk menghitung tingkat kolaborasi antar penulis adalah dengan metode Subramanyam (1983) dengan rumus:

\section{$\mathrm{C}=\frac{\mathrm{Nm}}{\mathrm{Nm}+\mathrm{Ns}}$}

\section{Di mana:}

$\mathrm{C}=$ tingkat kolaborasi penulis dalam suatu disiplin ilmu dengan nilai berada pada interval 0 sampai dengan 1 , atau $[0,1]$.

$\mathrm{Nm}=$ total hasil penelitian dari peneliti suatu disiplin ilmu pada tahun tertentu yang dilakukan secara berkolaborasi.

Ns = total hasil penelitian dari suatu disiplin ilmu pada tahun tertentu yang dilakukan secara individual.

\section{Keterangan:}

1) Apabila nilai $\mathrm{C}=0$, maka dikatakan bahwa hasil penelitian pada bidang tersebut seluruhnya dilakukan secara individual (penulis tunggal). 
2) Apabila nilai $\mathrm{C}$ lebih besar dari nol dan kurang setengah $(0<\mathrm{C}<0,5)$ maka dapat dikatakan bahwa hasil penelitian yang dilakukan secara individu lebih besar dibandingkan dengan yang dilakukan secara berkolaborasi.

3) Apabila nilai $\mathrm{C}=0,5$ maka penelitian yang dilakukan secara individual sama banyaknya dengan yang dilakukan secara berkolaborasi.

4) Apabila nilai $\mathrm{C}$ lebih besar dari 0,5 dan kurang dari $1(0,5<\mathrm{C}<1)$ dapat dikatakan bahwa hasil penelitian yang dilakukan secara individual lebih sedikit dibandingkan yang dilakukan secara berkolaborasi.

5) Apabila nilai $\mathrm{C}=1$ maka penelitian pada bidang tersebut seluruhnya dilakukan secara berkolaborasi.

\section{HASIL DAN PEMBAHASAN}

\subsection{Sebaran Artikel}

Sebanyak 50 artikel yang berhasil dihimpun pada tahun 2006-2016 menunjukkan kesamaan rata rata per-tahunnya, yaitu 5 artikel. Edisi jurnal yang memuat artikel tertinggi, yaitu pada tahun 2012 dan 2016 sebanyak 6 artikel (12\%), dan terendah 2007-2008 sebanyak 4 artikel (8\%). Produktivitas peneliti dalam penulisan artikel pada Jurnal Treubia sedikit mengalami kenaikan. Namun jurnal Treubia tetap menjaga konsistensi dalam perencanaan dan penyeleksian artikel per tahun sebanyak lima artikel (Tabel 1).

Tabel 1. Sebaran Artikel Treubia 2006-2016

\begin{tabular}{|c|c|c|c|c|}
\hline Tahun & Volume & Jumlah Nomor & $\begin{array}{l}\text { Jumlah } \\
\text { Artikel }\end{array}$ & $\%$ \\
\hline 2006 & 34 & 1 & 5 & 10 \\
\hline 2007 & 35 & 1 & 4 & 8 \\
\hline 2008 & 36 & 1 & 4 & 8 \\
\hline 2010 & 37 & 1 & 5 & 10 \\
\hline 2011 & 38 & 1 & 5 & 10 \\
\hline 2012 & 39 & 1 & 6 & 12 \\
\hline 2013 & 40 & 1 & 5 & 10 \\
\hline 2014 & 41 & 1 & 5 & 10 \\
\hline 2015 & 42 & 1 & 5 & 10 \\
\hline 2016 & 43 & 1 & 6 & 12 \\
\hline \multicolumn{2}{|c|}{ Total } & 10 & 50 & 100 \\
\hline
\end{tabular}

Produktivitas ke-50 artikel Jurnal Treubia memiliki muatan sumber acuan sebesar 1.307 jurnal, 307 buku (Gambar 1) dan kandungan sumber acuan yang tertinggi pada tahun 2011 (373 acuan). Kandungan acuan ini menunjukkan bobot pemikiran penulis sebagai kerangka dalam tulisan. Semakin tinggi sumber acuan primer yang digunakan sebagai sitiran maka kemungkinan besar mutu artikel tersebut semakin baik. Seperti pernah diungkapkan dalam Journal of Poultry Science bahwa jurnal (84,32\%) merupakan jenis dokumen yang banyak disitir (Haque, 2012). 


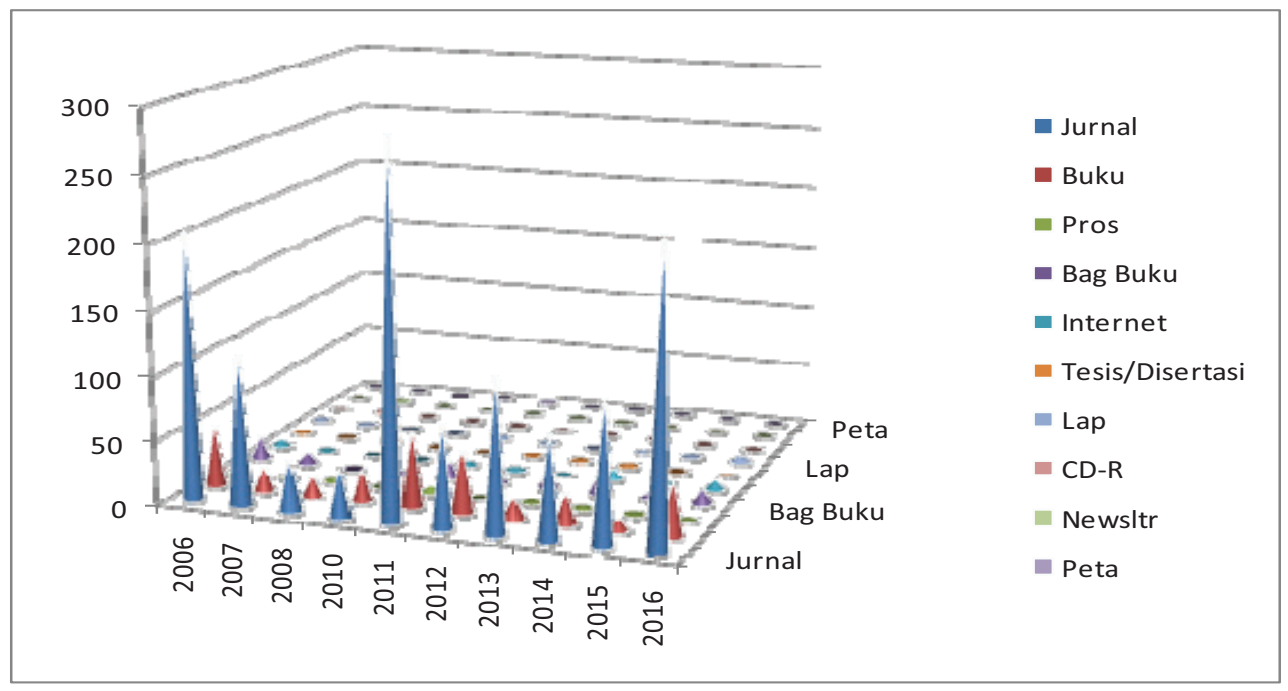

Gambar1. Jenis dokumen sitiran pada Jurnal Treubia 2006-2016

Capaian artikel yang dihasilkan oleh penulis pria sebanyak 71,1\% lebih besar penulis wanita $28,9 \%$ (Tabel 2). Melihat kondisi tersebut semestinya setiap institusi penulis dapat menempuh langkah pembinaan untuk meningkatkan produktivitas penulis wanita melalui bimbingan dari peneliti senior ke peneliti junior dan mengupayakan peran kolaborasi penelitian.

Tabel 2. Sebaran Artikel Berdasarkan Jenis Kelamin

\begin{tabular}{|c|c|c|c|c|c|}
\hline Tahun & Volume & Pria & Wanita & Jumlah & $\begin{array}{c}\text { Jumlah } \\
\text { artikel }\end{array}$ \\
\hline 2006 & 34 & 9 & 5 & 14 & 5 \\
\hline 2007 & 35 & 3 & 3 & 6 & 4 \\
\hline 2008 & 36 & 5 & 2 & 7 & 4 \\
\hline 2010 & 37 & 5 & 5 & 10 & 5 \\
\hline 2011 & 38 & 8 & 1 & 9 & 5 \\
\hline 2012 & 39 & 11 & 2 & 13 & 6 \\
\hline 2013 & 40 & 18 & 4 & 22 & 5 \\
\hline 2014 & 41 & 16 & 2 & 18 & 5 \\
\hline 2015 & 42 & 6 & 6 & 12 & 5 \\
\hline 2016 & 43 & 10 & 7 & 17 & 6 \\
\hline \multicolumn{6}{r|}{ Total } \\
\hline \multicolumn{2}{|c|}{ Persentase } & 71,1 & 28,9 & 100 & 50 \\
\hline
\end{tabular}

Sumber: Data primer yang diolah (2017)

\subsection{Pola Kepenulisan}

Ciri kepenulisan hasil penelitian yang dimuat dalam Jurnal Treubia 2006-2016 merupakan bentuk partisipasi satu hingga lebih dari tiga penulis (Tabel 3). Pola kepenulisan satu penulis menghasilkan artikel sebesar $30 \%$. Kondisi ini memperlihatkan bahwa pola kepenulisan individu menduduki posisi rendah dalam memecahkan persoalan taksonomi 
hewan dibandingkan berkelompok. Sejalan dengan penelitian yang berskala internasional mengenai nanoteknologi ternyata tingkat pelaksanaan penelitiannya dilakukan oleh satu hingga lebih dari tiga peneliti, dan hasil kolaborasinya memiliki rerata sebesar 0,9 lebih (Karpagan, 2013). Berbeda dengan kajian kepenulisan pada ilmu-ilmu sosial di mana kepenulisanan perorangan sangat tinggi (Purnomowati, 2004).

Tabel 3. Pola Kepenulisan pada Jurnal Treubia 2006-2016

\begin{tabular}{|c|c|c|}
\hline Kepenulisan & Artikel & Prosentase \\
\hline satu penulis & 15 & 30 \\
\hline dua penulis & 12 & 24 \\
\hline tiga penulis & 14 & 28 \\
\hline empat penulis & 4 & 8 \\
\hline lima penulis & 2 & 4 \\
\hline enam penulis & 1 & 2 \\
\hline tujuh penulis & 2 & 4 \\
\hline Total & 50 & 100 \\
\hline
\end{tabular}

Sumber: Data primer yang diolah (2017)

Bentuk lain pola kepenulisan perorangan dan gabungan setiap tahun selama 2006-2016 menunjukkan bahwa kepenulisan lebih dari satu penulis memiliki kemunculan terbanyak dibanding satu penulis (Tabel 4).

Tabel 4. Kepenulisan Perorangan dan Gabungan pada Jurnal Treubia 2006-2016

\begin{tabular}{|c|c|c|c|c|}
\hline Tahun & Volume & $\begin{array}{c}\text { Satu } \\
\text { Penulis } \\
\text { (Ns) }\end{array}$ & $\begin{array}{c}\text { Penulis } \\
\text { Gabungan } \\
(\mathrm{Nm})\end{array}$ & $\begin{array}{c}\text { Tingkat } \\
\text { Kolaborasi } \\
\mathrm{C}=\mathrm{Nm} / \mathrm{Nm}+\mathrm{Ns}\end{array}$ \\
\hline 2006 & 34 & 1 & 4 & 0.8 \\
\hline 2007 & 35 & 2 & 2 & 0.5 \\
\hline 2008 & 36 & 2 & 2 & 0.5 \\
\hline 2010 & 37 & 2 & 3 & 0.6 \\
\hline 2011 & 38 & 2 & 3 & 0.6 \\
\hline 2012 & 39 & 3 & 3 & 0.5 \\
\hline 2013 & 40 & 0 & 5 & 1 \\
\hline 2014 & 41 & 1 & 4 & 0.8 \\
\hline 2015 & 42 & 1 & 4 & 0.6 \\
\hline 2016 & 43 & 1 & 5 & 0.83 \\
\hline \multicolumn{2}{|c|}{ Total } & $15(30 \%)$ & $35(70 \%)$ & 0.7 \\
\hline
\end{tabular}

Sumber: Data primer yang diolah (2017)

Untuk menentukan derajat kolaborasi secara kuantitatif pada Jurnal Treubia digunakan rumus Subramanyan (1983): $\mathrm{C}=\mathrm{Nm} /(\mathrm{Nm}+\mathrm{Ns})$, di mana notasi "C" diartikan sebagai tingkat kolaborasi, "Nm" adalah jumlah artikel yang dihasilkan lebih dari satu penulis, notasi "Ns" adalah jumlah artikel yang dikontribusikan satu penulis, dan nilai "C" dinyatakan dalam satuan persentase (\%). Hasil yang diperoleh setelah perhitungan menunjukkan rerata tingkat 
kolaborasi jurnal mencapai angka $70 \%(0,7)$ melebihi standar keseimbangan sebesar $50 \%$ $(0,5)$.

Beberapa jenis karakteristik kepenulisan yang dapat diolah berdasarkan negara asal penulis (Tabel 5). Indonesia menempati posisi penulis teratas sebanyak $86(67,19 \%)$, posisi kedua negara Jepang $30(23,44)$ dan terendah Australia, Singapura dan Vietnam 1 artikel $(0,78 \%)$. Kondisi ini dapat dikatakan bahwa Jurnal Treubia diterbitkan di Indonesia dan penulis pada jurnal tersebut lebih banyak berkolaborasi dengan negara Jepang.

Tabel 5. Kontribusi Pengarang berdasarkan Negara

\begin{tabular}{|l|c|c|}
\hline \multicolumn{1}{|c|}{ Negara } & Jml Kontribusi (Penulis) & Prosentase \\
\hline Amerika & 6 & 4.69 \\
\hline Indonesia & 86 & 67.19 \\
\hline Jepang & 30 & 23.44 \\
\hline Perancis & 3 & 2.34 \\
\hline Australia & 1 & 0.78 \\
\hline Singapura & 1 & 0.78 \\
\hline Vietnam & 1 & 0.78 \\
\hline & 128 & 100 \\
\hline
\end{tabular}

Dari hasil pengumpulan artikel pada Jurnal Treubia 2006-2016 kemudian dilakukan pengolahan untuk mengetahui produktivitas penulis pada jurnal tersebut. Perhitungan mengenai rerata penulis per artikel bervariasi (Tabel 6). Maksimum penulis per-artikel ada pada tahun 2013 sebanyak (18,3\%) dengan rerata 4,4 dan minimum penulis per artikel ada pada tahun 2007 sebanyak (5\%) dengan rerata 1,5. Hal ini menunjukkan ada peningkatan rerata penulis per artikel meskipun berfluktuatif setiap tahunnya dengan rerta sebesar 2,56. Sejalan dengan penelitian terdahulu bahwa rerata penulis pada jurnal bidang biologi 3,97 (Cunningham dan Dillon (1997). Sedangkan untuk jumlah artikel setiap tahunnya relatif konstan dengan rerata setiap tahun sebanyak 5 artikel.

Tabel 6. Rerata Indeks Penulis Per-Artikel

\begin{tabular}{|c|c|c|c|c|c|}
\hline Tahun & Volume & Jumlah Artikel & Jumlah Penulis & Prosentase & AAPP* \\
\hline 2006 & 34 & 5 & 14 & 11.7 & 2.8 \\
\hline 2007 & 35 & 4 & 6 & 5.0 & 1.5 \\
\hline 2008 & 36 & 4 & 7 & 5.8 & 1.75 \\
\hline 2010 & 37 & 5 & 10 & 8.3 & 2 \\
\hline 2011 & 38 & 5 & 9 & 7.5 & 1.8 \\
\hline 2012 & 39 & 6 & 13 & 6.7 & 2.17 \\
\hline 2013 & 40 & 5 & 22 & 18.3 & 4.4 \\
\hline 2014 & 41 & 5 & 18 & 15.0 & 3.6 \\
\hline 2015 & 42 & 5 & 12 & 9.2 & 2.4 \\
\hline 2016 & 43 & 6 & 17 & 12.5 & 2.83 \\
\hline \multicolumn{2}{|c|}{ TOTAL } & 50 & 128 & 100.0 & 2.56 \\
\hline
\end{tabular}

*Average No. of Author per Paper

Sumber: Data primer yang diolah (2017) 


\section{KESIMPULAN}

Berdasarkan hasil analisis menunjukkan bahwa sebaran Jurnal Treubia selama 10 tahun (2006-2016) sebanyak 50 artikel dengan jumlah artikel tertinggi pada tahun 2012 dan 2016 yang memuat 6 artikel (12\%). Jumlah sitiran Jurnal Treubia selama 10 tahun sebanyak 1.784 sitiran didominasi oleh jurnal $(73,26 \%)$ dan buku $(17,2 \%)$. Penulis pria $(71,1 \%)$ lebih banyak dari penulis wanita. Pola kepenulisan selama tahun 2006 - 2016 memiliki ciri bahwa frekuensi lebih dari satu penulis memiliki kemunculan terbanyak dibandingkan satu penulis dengan tingkat kolaborasi kepenulisan bersama $70 \%(0,7)$. Dari sebanyak 7 negara yang dikaji, penulis Indonesia menduduki posisi terbanyak (67,19\%). Dalam pengembangan ilmu pengetahuan, kajian ini dapat digunakan dalam pemeringkatan jurnal, sehingga dapat mencerminkan kedudukan atau tingkat jurnal serta meningkatkan reputasi terkait pemeringkatan jurnal. Penulis menyarankan perlu dibuat kebijakan oleh pengelola jurnal dan tim pembina jurnal untuk meningkatkan kepenulisan dengan berkolaborasi dengan peneliti asing. Hal tersebut dilakukan agar dapat meningkatkan kualitas Jurnal Treubia menuju internasionalisasi jurnal. Kajian ini diharapkan bermanfaat untuk mengetahui kualitas artikel dan tingkat kolaborasi penelitian penulis pada jurnal Treubia 2006-2016 dan memberi manfaat bagi pemangku kepentingan khususnya di Puslit Biologi-LIPI dalam merencanakan kegiatan kerjasama riset dengan peneliti asing, sehingga hasil kerjasama dapat dituangkan dalam Jurnal Treubia untuk meningkatkan aksesibilitas secara global.

\section{DAFTAR PUSTAKA}

Aliyu, Murtala. 2011. Author Productivity and Colaboration Among Academic Scientists in Modibbo Adama University of Technology, Yola. The Information Manager, 11(1\&2): 3235 .

Arya, Chanda andSharma, Superna. 2012. Authorship Trends and Collaborative Research in Veterinary Sciences: A Bibliometric Study. Chinese Librarianship: an International Electronic Journal, 34: 38-47.

Cunningham, Sally Jo and Dillon, Stuart M. 1997. Authorship Pattern in Information Systems. Scientometrics, 39(1): 19-27.

Das, Prabir Kumar. 2013. Journal of Informetrics: A Bibliometric Profile. DESIDOC Journal of Library \& Information Technology, 33(3): 243-252.

Glänzel, W. 2003. Bibliometrics as a Research Field. A Course on Theory and Applications of Bibliometric Indicators.

Haque, Md. Enamul. 2012. The Journal of Poultry Science: an Analysis of Citation Pattern. The Eastern Librarian, 23(1): 64-73.

Kadarsan, S. 1994. Satu Abad Museum Zoologi Bogor. Balai Penelitian Bidang Zoologi, Puslitbang Biologi-LIPI.

Karpagan, R., Gopalakhrisna, S. and Babu, B. Ramesh. 2011. Publication Trend on Nanotechnology among G15 Countries: a Bibliometrics Study. Collnet Journal of Scientometrics and Information Management, 5(1): 61-80. 
Katz, J. Sylvan and Martin, Ben R. 1997. What is Research Collaboration?. Research Policy, 26(1): $1-18$.

Pritchard, A. 1969. Statistical Bibliography: an Interim Bibliography. Journal of Documentation, 25: $348-349$.

Raptis, P. 1992. Authorship Characteristics in Five International Library Science Journals. Libri, 47: $35-52$

Purnomowati, Sri. 2004. Ciri-Ciri Kepengarangan dan Penggunaan Literatur dalam Majalah Indonesia Bidang Ilmu-Ilmu Sosial. BACA: Jurnal Dokumentasi dan Informasi , 28(1): 1-14.

Subramanyam, K. 1983. Bibliometrics Studies of Research Collaboration: a Review. Journal of Information Science, 6: 33-38.

Sulistyo-Basuki, 2002. Bibliometrika, Sainsmetrika, dan Informaterika. Kumpulan Makalah Kursus Bibliometrika. Jakarta: Masyarakat Informetrika Indonesia. 